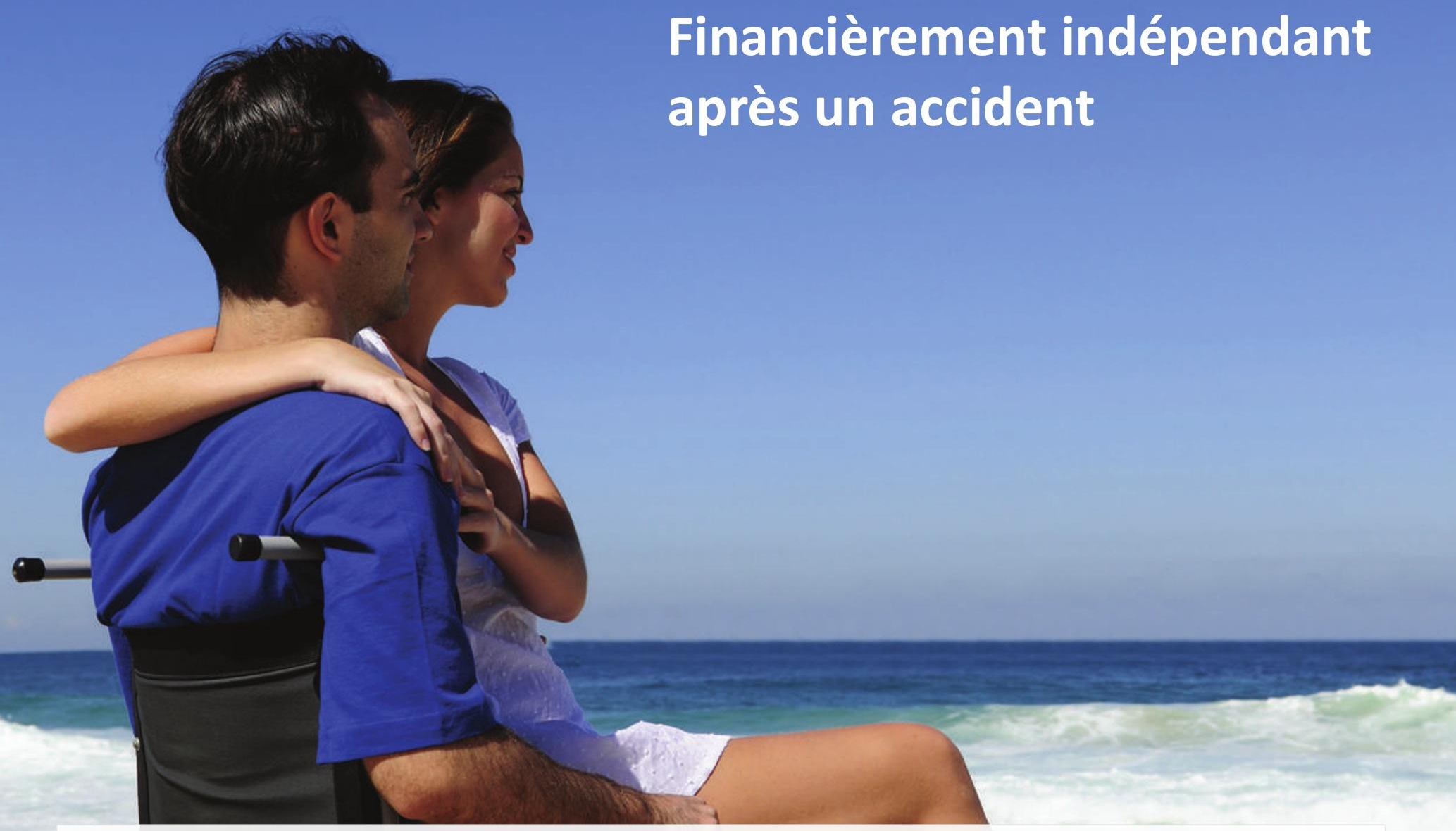

Les suites d'un accident peuvent avoir d'affreuses conséquences. En qualité de médecin vous risquez en cas de perte d'un index de ne plus pouvoir exercer votre activité ou d'une manière très restreinte. Auprès des assurances sociales vous êtes considéré comme capable d'exercer une activité et vous ne bénéficiez - et ceci qu'éventuellement - que d'une prestation sociale réduite.

L'assurance accidents individuelle FMH Insurance Services a été développée pour de telles situations. Pour une prime annuelle de CHF 276.- pour femmes et CHF 380.- pour hommes, vous recevez lors d'un grave accident une prestation en capital jusqu'à CHF 1050 000.-. Nous vous envoyons volontiers de plus amples renseignements à ce sujet.

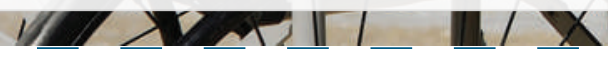

\title{
ASSURANCE ACCIDENTS INDIVIDUELLE
}

$\square \quad$ Je veux être financièrement indépendant. Envoyez-moi des informations sur l'assurance accidents individuelle.

$\square \quad$ Je désire être conseillé. Téléphonez-moi.

$\square \quad$ Je suis intéressé par un conseil global sur la prévoyance et/ou une planification financière.

Prénom / Nom

Adresse

NPA / Lieu

Tél. privé / prof.

Atteignable de préférence vers

Adresse mail

\section{FMH INSURANCE SERVICES}

Roth Gygax \& Partner AG - Service de coordination Moosstrasse 2, 3073 Gümligen Tél. 0319595000 - Fax 0319595010 mail@fmhinsurance.ch - www.fmhinsurance.ch 